\title{
INSTITUTIONAL CO-OPERATION MODELS FOR ENHANCED UTILIZATION OF RESEARCH INFRASTRUCTURE IN THE BSR: CASE OF LATVIA
}

\author{
Aivars Timofejevs ${ }^{1,2}$, Valdis Avotins ${ }^{3,4}$ \\ ${ }^{1}$ Stockholm School of Economics in Riga, Latvia; ${ }^{2}$ Oxford Research Baltics, Latvia; \\ ${ }^{3}$ Ventspils University of Applied Sciences, Latvia; ${ }^{4}$ Riga International School of Economics and \\ Business Administration, Latvia \\ aivars.timofejevs@sseriga.edu, valdis.ventspils@gmail.com
}

\begin{abstract}
The aim of this study is to analyse cross institutional co-operation of scientific institutes in the Baltic Sea Region. This is done by assessing the outcomes from eight expert panel discussions at national and the Baltic Sea Region level. This was done for three science areas: material science, life sciences and welfare state. Furthermore, sectorial and consolidated conclusions were validated by international experts. Aggregated analyses were conducted using previous results at standardised five criteria framework and compared to similar research performed by other BSR countries. This study was aimed to analyse and identify main factors determining the development of sustainable and long-term collaboration around existing or new different size research infrastructures, to assess catalysing mechanisms for the growth of local and transnational user base as an efficient new knowledge creation, commercialisation and innovation base around RIs. Differences in shortand medium-term strategic objectives, and funding allocations, dominance of competition factors over collaboration, and motives for joint actions need to be considered in order to increase research performance and facilitate transnational collaboration in the BSR. Collaboration in the use of scientific infrastructure can be productive, if we jointly collect external talent or destructive, if it is limited by brain drain policy and fierce competition for talent implemented by research facility owners or operators. The study identifies the impact of key factors, contradictions and shortcomings, which has led to the development of consolidated conclusions, recommendations for increasing the capability of large-scale science facilities through the improved co-operation models. The last also includes elaborated analysis of the governance models for the research infrastructure.
\end{abstract}

Keywords: large-scale research facility, research infrastructure, co-operation, talent attraction.

\section{Introduction}

Penetration of digital technologies, artificial intelligence, industrial revolution 4.0 and development of future's technologies in many cases were driven by concentration of resources and global collaboration of research. The EU and nation-wide innovation policies aim to concentrate and consolidate resources for research and research infrastructures (RI), leading to regional research specialisation and increased role of large-scale research infrastructures (LSRI) at the European Strategy Forum on Research Infrastructures (ESFRI). However, the concentration is leading to some positive effects like economies of scale and synergies, as well as some negative in particular in smaller and less wealthy countries, e.g. brain drain (2) decreased long term productivity (3), as well as decreased wellbeing due to disruption of social networks and disturbed family life [1]. Larger and more wealthy countries also are more competitive in terms of financial support for scientists, namely, they can provide larger salaries that in turn increases the willingness to move to other countries [2]. Consequently, this research is focused on how to develop new or improve the existing co-operation models between scientific institutes in different countries that would allow to eliminate the negative effects while emphasising the positive ones. This workis based on the obtained outcomes discussed at national and the Baltic Sea Network project-wide expert panels and, finally, analysing all available outcomes with the aim to design LSRI roadmap (About the project read more at https://www.balticscience.org/).

\section{Methodology}

The analysis at the core of this paper is structured in the following areas of research excellence (more about selection criteria see at [3], p.6):

- materials, photon and neutron science;

- life sciences including biomedical research, biomedicine, diagnostics, and drug development;

- the welfare state.

As opposed to aggregative methods (which summarise well-specified data and stable concepts), we used the critical interpretive approach based on induction and interpretation to develop concepts 
and integrate them with theories. Based on that, an attempt to consolidate the observations creates a main research question: how different RI governance approaches facilitate collaboration between the RI of different scales without having a negative impact on any of the parties? [4].

For each selected scientific sector two-level expert panels at national (in April, 2018) and the Baltic Sea Region level (in April-November, 2018) were created in order to discuss topics identified from the previous research: financing and costs of RI, policies concerning the selected science domains and RI, the importance of scientist retention, scientific cooperation, topics of joint interest for future multilateral research collaboration, support for scientists, and promotion of RI usage. During the fourth joint national working group discussion in May, 2018, experts from all three sectors addressed the following issues, insufficient funding for RI, insufficient cooperation, the value of long-term strategies, and lack of qualified research personnel in certain science domains. Problem-solutions to these challenges have also been discussed. Also, it has been found that there might be certain commonalities of issues identified across the three selected science areas, with some exceptions that are outlined in this study.

In addition, within the framework of this working document, the BSN-wide discussion results of the scientific experts organized within scope of the BSN project (April-October, 2018) were analysed covering the excellence field in photon and neutron science, structural research, life sciences (in particular biomedical research, diagnostics and drug development) and the welfare state.

Additionally, six (two for each field of scientific excellence) international expert interviews were performed to validate the obtained conclusions. During the interviews, the importance of transparency and openness in RI access policies, the lack of funding for new and operation of existing RI (OPEX), the importance of training of new scientists and RI personnel, and the cooperation development were discussed.

\section{The Baltic Sea Region Framework Conditions}

Although the BSR has advanced and top-ranked universities and research institutions, the research performance between the countries in the BSR remains different. High differences in economic wealth, investment amounts in research and technological development (RTD) lead to growing brain and talent concentration around existing and emerging higher education and research ecosystems [5], where RIs and LSRIs obtain dominant role for science excellence and knowledge commercialisation. LSRI facilities are not equally distributed across the macro-region [6]. Large available cohesion funds for less developed countries and geographic proximity in one BSR form common interests and serve as a motivator for transnational cooperation. However, national interests to compete for EU-wide research funds limit such cooperation by segments where interests and areas of excellence are overlapping [6]. In general, there is a consensus about will, readiness and RTD cooperation opportunities present at the BSR arena. This paper is designed to help the governments of the BSR take advantage of these opportunities and enhance the macro-regional RI cooperation on win-win conditions so, as to reach the goals set out in the BSR strategy. Scientific publications that originate from collaborative research projects in the BSR on average are of higher scientific quality than those which do not. Joint investment and shared operating costs allow for the creation of more competitive science infrastructures and favourable conditions for the development of broader competences for their exploitation. The internal mobility leads to brain drain, while young talent mobility from outside the BSR increases the macro-region's scientific capacity [7]. Only value-added activities for all states provide further motives to facilitate research cooperation in the macro-region.

Table 1

Main factors determining performance of scientific excellence and exploitation of the RI

\begin{tabular}{|c|c|c|c|}
\hline \multicolumn{3}{|c|}{ Pillars } \\
\hline Funding & Co-operation & Strategy & Personnel \\
\hline $\begin{array}{c}\text { Consistency, } \\
\text { Sustainability }\end{array}$ & $\begin{array}{c}\text { Sufficiency, } \\
\text { efficiency }\end{array}$ & $\begin{array}{c}\text { Long term planning, } \\
\text { Transparency, } \\
\text { Openness }\end{array}$ & $\begin{array}{c}\text { Qualified personnel, sufficient number } \\
\text { of researchers, sufficient amount of } \\
\text { technicians }\end{array}$ \\
\hline
\end{tabular}

The selected six European LSRI case studies, by two in each of priority for research sectors helped provide broader insight into the different practices in operations of LSRI and in particular in 
the different strategies to attract talent and increase user base [5;8]. The main criteria, determining LSRI performance were described as openness, transparency, support for users, financing, projectbased governance, promotion, competitiveness to attract financing from the EU Horizon2020 program, advancement of developed E-infrastructure and ICT infrastructure.

\section{Four Main Pillars}

Based on the discussions of Latvian experts, international experts from the BSR and the toolbox of best practices, the four main factors concerning the development of RI in the BSR are identified.

The opinion of both Latvian and international experts mostly overlaps, which is an indication of the importance of these topics and of the underlying issues. Also, the identified factors are similar in different fields of scientific excellence and, therefore, are stated for the three fields together.

Here it should be emphasised that the aim of the current research is to assess the performance of RI and outline key factors determining cooperation around RIs, leading to higher levels of RI utilisation.

\section{Funding}

This section briefly outlines the existing shortfalls in funding practices, where apparent lack of comprehensive approach to the various financial components of establishing and running an RI known for its delivered science excellence, are being singled out. Funding for RI, e.g. institutional funding (base funding as competitive institutional funding), especially for the maintenance and service of RI, and for the training of scientists and RI personnel is not sufficient in many areas, especially in the field of the welfare state as emphasized by experts in the final working group seminar (The final working group seminar. June 27th, 2018. Riga Technical University Conference Hall, Āzenes street 6, Riga, Latvia). In fact, the ESIF programmes do not cover the maintenance, repairing, updating costs of RI; therefore, buying new RI instead of maintaining the existing RI, which is more expensive and oftentimes ineffective, is implicitly promoted by the EU funding rules. Also, RI funding is inconsistent and unsustainable, i.e. a project may be started, but there might be lack of resources to finish it, or RI is being funded, but the training of personnel who uses the RI is not. Therefore, maintenance is being funded by other project funds and grants, which is not always appropriate or in favour of sustainable operation of the RI. The issues concerning the long-term sustainability of RI are also recognized on the European level (Long term sustainability of Research Infrastructures. Non-paper Stakeholders Workshop of 25th November 2016). In addition, it is emphasized by experts in the Latvian working group seminars that dedicated funding for research collaboration is insufficient or even non-existing. All above mentioned issues facilitate brain drain, negatively affect the attractiveness of smaller institutions as co-operation partners.

Therefore, Latvian experts from all sectors agreed, that Governmental target funding should be provided for the maintenance of RI, for the technical support of RI, for the support of international standards, and for the sustainable reward system to RI personnel.

\section{Cooperation}

It is emphasized by experts, both Latvian and international, that due to important positive aspects that could potentially be achieved, like the promotion of innovation, visibility, and recognition, and enhancing and increasing cooperation between researchers based in the BSR is important. The importance of international visibility is further elaborated - in order to attract more RI users and collaboration projects, the effectiveness of RI should be advertised and maintained. One of the means for the advertisement and proofing of the efficiency of an RI are publications with examples of successful projects. Also, it is noted that one of the limiting factors for cooperation is the overloading of certain RIs (mostly physical RIs), meaning that researchers are often not able to use heavily demanded RI. However, some parts of experiments and other research activities could be conducted in other - smaller facilities thus decreasing the overload of the larger ones. This clearly indicates that currently the co-operation is not sufficient. At the same time, the efficiency is somewhat improving, since larger institutes sometimes use the capacity of smaller institutes in case of local overload. Free, open and transparent access to LSRIs is a key for highly efficient performance, as well as the international visibility of both scientists and RIs. 


\section{Strategy}

Implementation of long-term operation and funding strategies is not promoted - there is a need for a long-term strategy that is coordinated within the RI development programme of the structural funds of the EU and a need for monitoring and control of such strategy on the level of the BSR. Next step would be to ensure that those strategies are made transparent and open for other scientists and RI.

\section{Personnel, Researchers and Scientists}

Declining demographic trends in the BSR countries and insufficient funding for training of personnel for specific RI, especially in the EU13 countries, is resulting in an overall shortage of qualified RI personnel, scientists and researchers. Hence, the research potential of the macro region is not fully exploited, if the personnel shortages are not addressed properly.

In the following part of this paper, ways of addressing the issues concerned with the four pillars of RI and RI cooperation development in the BSR are discussed. Suggestions are provided for the respective policy makers in the BSR countries in the three fields of scientific excellence as identified earlier.

\section{Facilitating Mechanisms}

In this chapter, overall suggestions concerning more efficient utilization of RI through the increased co-operation are provided mainly for the policymakers of the BSR countries, with several suggestions for RIs and RI holder institutions. The suggestions are split into two subcategories: facilitating mechanisms, which include the necessary conditions for successful RI cooperation in the BSR, and motivational elements, which further provide ways to enhance RI cooperation in the BSR. The facilitating mechanisms are more related to the structures, interaction tools and mechanisms whether the motivational elements are more personal related to researchers and ways to influence a decision about more active use of RI. Then, suggestions are stated based on the four pillars that were identified in the final working group discussions (The final working group seminar. June 27th, Riga Technical University Conference Hall, Āzenes street 6, Riga, Latvia), the interviews, and the case studies.

\section{Funding}

Increased funding for RI should be developed with a focus on development, investment and maintenance needs. The funding schemes should be developed in a more integrated manner (e.g. EU funding and National financing) with the focus on sustainable development of both RI as such, as well as personnel both scientific and technical. It is equally important to create long-term financial plans, which are coordinated on a national level across institutions and on an international level across the BSR countries. Funding schemes in the future should be more oriented towards measurable goals and achievements, or in other words, solutions that are expected from the scientific institutions. Financing mechanisms in the future should address the challenge of finding the balance between advantages provided by a larger concentration of scientific excellence (critical mass) and economies of scale on the one hand and brain drain caused by the gravity processes on the other.

Both local and international experts involved in the research also agreed on the importance to develop appropriate fiscal benefits for enhanced co-operation. Also, the best practices in public procurements should be promoted between countries to facilitate economic efficiency of RI that in turn will increase its attractiveness as a co-operation partner. In the future more funding should be provided for joint cross-border research projects, especially the ones oriented to achieve clear and measurable goals.

\section{Cooperation}

The main preconditions for successful cooperation are openness and transparency, therefore, openness and transparency plans for each RI object should be developed and implemented by RIs. These plans should include clear conditions, terms and rules on the use of RI, the costs of RI, the collaboration process involving the RI. This would also include support for participation in different consortiums, projects and joint applications developed. The co-operation component should be included as an additional advantage for project applicants. The information relevant for co-operation enhancement should be developed in a clear and constructive manner. This information should be distributed through the appropriate information channels, e.g. websites, databases, publications, conferences, seminars etc. The information channels also should include responsible ministries and 
other institutions. Ministries, in turn, should proactively communicate with RI representatives to identify the co-operation opportunities, develop optimal support measures and support credible and appropriate partnerships. The possible cooperation forms and cooperation promotion activities are as follows.

1. Creation and development of national RI nodes (e.g. part of ESFRI and ERIC).

2. RI consortiums; three main strategic tasks can be identified: participation in RI consortiums, initiation of participation in RI consortiums, management of and leadership in RI consortiums.

3. Promotion of participation in RI projects; provide support with the lowest possible administrative burden for the application preparation and submission, which would lead to more accepted applications.

Currently insufficient attention is paid to the development of networking activities; however, this was identified as important pre-condition for co-operation in the future. So, more support for networking activities should be provided.Remote access is another aspect that should be ensured to enhance co-operation. This will be especially beneficial, if developed in line with networking activities.

\section{Strategy}

According to the aforementioned, there should be a clear strategy for the development of openness, promotion of RI, and research collaboration. The strategy should be publicly available and easily accessible, in order to attract and retain the possible collaboration partners. As discovered in the case study analysis, working group discussions and interviews with experts, such a strategy might include the following activities and concepts.

1. Assessment of opportunities to enrol in international research consortiums, ERIC in particular, which provides benefits (e.g. new and larger networks of scientists, prestige, more funding possibilities etc.) for local institutions and researchers.

2. A clear definition of national level RI and provision of target funding for the maintenance and development of a strategy for the national level RI.

3. Provision of funding for medium-scale RI (while small-scale RI can still be financed internally by higher education institutions).

4. Enhanced public-private partnerships including opportunities for cross border co-operation.

5. Develop mechanisms for in-kind contribution by small RI representatives.

6. Adjust co-financing principles to the general income level of each participating country.

It is important that strategies are aligned with other RI on a general level and on a level of fields of scientific excellence, i.e. strategies should be harmonised, not conflicting. If more coordination is achieved, more synergies are expected to appear. In fact, in the long-term, strategies and business models for RI should be harmonised between countries as well. The urgency of this RI aspect should be pointed out, since, for example, in the Swedish context it has been recognised that the funding aspect has grown in importance over the last years due to the steady rise of infrastructure costs, which are expected to increase further in the future (Baltic TRAM, October, 2017, Swedish Innovation and Smart Specialisation Governance in the Baltic Sea Region's Context: Towards an Enhanced MacroRegional Science-Business Cooperation). While the aforementioned suggestions are mostly addressed to the policymakers in the BSR, the following suggestions are provided for RI in particular:

1. Creation of sustainable long-term and personnel development plans with risk analysis and prevention strategies. It is important that personnel development plans are integrated together with infrastructure development plans. Such a strategy also will facilitate co-operation between RIs.

2. Creation of business-oriented financial plans for inclusion in long-term strategies.

3. The attraction of additional financial resources for RI from a wider variety of public and private sources supplementing the already provided funding.

4. Monitoring of the RI: costs of RI and costs associated with the use of RI, depreciation of RI, the track of RI usage, etc.

\section{Personnel, Researchers and Scientists}

To solve the RI personnel and researcher shortages, it is suggested for RI in particular to:

1. create mechanisms to support the development and retention of new scientists and researchers; 
2. prepare the RI personnel, researchers and scientists for international cooperation providing the opportunity for them to become the coordinators of RI utilisation;

3. create unified and aligned plans for the development of RI and RI personnel, researchers and scientists;

4. require the RI personnel, researchers and scientists to take part in at least a minimum amount of mobility events, which should be included in long-term RI development strategies;

5. create RI engagement programmes and organise summer schools, workshops, courses for students;

6. develop financial incentives for scientists to return to the home institution after mobility actions and international exchange;

7. develop incentives for each scientific institution to accumulate a sufficient amount of competence and excellence to trigger gravity- namely, attraction of scientists from other countries.

\section{Motivational Elements}

\section{Funding}

In order to reduce the portion of idle RI, investment in RI should come together with investment in the development and retention of personnel, researchers and scientists. In addition, a long-term financial support programme has to be created for RI personnel, scientists and researchers to visit foreign RI. Also, dedicated financing should be provided for the support (e.g. courses, summer schools, workshops, seminars, and training) of personnel and scientists in order to increase the motivation to participate in more cooperation and research projects. Sustainability and predictability of the funding are important motivators for scientists to engage and remain active in different research projects.

\section{Cooperation}

RI objects should be well documented, i.e. all the necessary information concerning technical attributes of the RI, as well as user manuals should be provided in a clear, accessible, and structured way. In addition, high-quality publications, portals, databases with data about RI possibilities, webinars, and conferences are also regarded as good means for the development of research cooperation, which together with plans for openness and transparency would form the core for the attraction of collaboration partners. Promising preconditions for ensuring the overall availability of data and research delivered by RI housed by the BSR are testified by several of LSRI captured in a list of institutions endorsing the EOSC Declaration (European Commission, November 24, 2017, list of institutions endorsing the EOSC Declaration), such as ESS-ERIC and the European XFEL GmbH. All the above-mentioned aspects are identified as important and even crucial to enhance motivation to participate in more cross-border cooperation.

\section{Strategy}

To attract and retain researchers and scientists, and increase the number of collaboration projects, the following strategic activities and conceptions are suggested.

1. Creation of databases containing data about research collaboration possibilities, research projects, available RI, application guidelines, etc. This should be accompanied by motivational instruments for submission of data and information to this database.

2. Provision of digitalisation and availability of data and ICT support for RI.

3. Availability of RI for external users at the preferential price (free of charge when possible) on condition that the results of the research will be publicly available (open access).

It is important to note that scientific data life cycle involves a set of sophisticated operations and processes that require permanent and long-lasting investments, especially in the field of welfare state.

\section{Conclusions}

The development of the models for enhanced cooperation in the BSR included extensive research on both primary and secondary sources. In this process, a number of significant discoveries were made and suggestions developed. Regarding the general BSR strategic vision for the future, a number of aspects were identified. 
1. Increased cross-border cooperation and co-utilisation of research facilities will be facilitated and promoted, and is expected to become a more usual way of working.

2. The EU-14 centres of excellence would benefit from cooperation with the EU-13 Public Research Organisations (PRO), if the EU-13 PROs especially the development plans and strategies are aligned taking into account the strategic research priorities expressed in measurable performance indicators.

3. New and more innovative co-operation models, e.g. virtualization is needed to ensure the benefits and synergies of co-operation, but at the same time avoiding brain drain caused by gravity of larger infrastructures.

4. Exchange of scientific research services is already used as a tool to overcome the cost differences between more "expensive" and "less expensive" countries and such co-operation model should be facilitated in the future as well.

5. More extensive, aligned and coordinated development of joint cross-countryresearch strategies will contribute to more efficient use of resources and increased competitiveness of the macroregion.

6. The attraction of global talents outside the macro-region [5] was and will be on the agenda for all BSR countries and co-operation between the institutions within the region will facilitate the talent inflow.

7. The financial support (government and EU funding) should be provided with more focus on long term co-operation networks with aligned and goal-oriented research strategies. This will accelerate the innovations and scientific development in the region.

The key factors for the cooperation development are the scale or size of the RI, uniqueness, existing strategy for development, cooperation facilitation mechanisms, personnel-related issues for support development and attraction of the talent. All those factors should be assessed and addressed in an integrated manner, since no-one of them alone is sufficient to provide a significant impact.

\section{Further research}

The current research was focused on the assessment of the preconditions and models for enhanced co-operation between scientific institutes of different sizes and in different locations. The issues not addressed in this paper can be elaborated in the future research by the deeper analysis of internal and external factors for RI that could determine more efficient implementation of the suggested models.

\section{References}

[1] Azoulaya P., Ganguli I., Graff Zivinc J. The mobility of elite life scientists: Professional and personal determinants, 2016, 38 p. NBER Working Paper No. 21995, availableat https://www.nber.org/papers/w21995, accessed at 18.03.2020.

[2] Ackers L., Internationalisation, Mobility and Metrics: A New Form of Indirect Discrimination? 2008.

[3] Timofejevs A., Avotins V., Skutans V. Roadmap for transnational utilisation of existing and planned R\&I Infrastructure. BSN publication, 2019. Available at: https://www.balticscience.org/bsn-publications/reports-working-papers/, accessed at 18.03.2020.

[4] Autio E. Innovation from big science: enhancing big science impact agenda, Department for Business, Innovation and Skills, London, 2014.

[5] Bagdanavičius J., Jodkoniene Z. Brain drain from Lithuania: The attitude of civil servants, 2008.

[6] Ministry of Education and Research of Republic of Estonia, Research Policy Department. Drivers for Participation in Transnational Research Cooperation, Recommendations for Increasing Participation of Low Performing Countries and Regions in Transnational Research Activities. BSN publication, 2018.

[7] Sepponen S., Roschier S., Bröckl M., Mikkola J. and Hjelt M., Gaia Consulting Ltd. (March 2018). Researcher mobility tools for the Baltic Sea Region. [online] [18.03.2020] Available at: https://www.baltic-science.org/lana-download/researcher-mobility-tools-for-the-baltic-sea-region/

[8] Fernández-Zubieta A., Geuna A., Lawson C., Productivity Pay-offs from Academic Mobility: Should I stay or should I go? 2016. 